\title{
EVALUACIÓN TOXICOLÓGICA PRELIMINAR DE RUTA GRAVEOLENS, ORIGANUM VULGARE Y PERSEA AMERICANA SOBRE EMBRIONES PREIMIPLANTACIONALES DE RATÓN
}

\section{PRELIMINAR TOXICOLOGICAL ASSESSMENT OF Ruta graveolens, Origanum vulgare and Persea americana ON THE PREIMPLANTATIONAL MOUSE EMBRYOS}

\author{
V. Benavides, G. Trujillo, G. D’Arrigo, U. Paredes y J. Pino
}

\section{RESUMEN}

El creciente interés por la medicina natural hace necesaria la evaluación de las propiedades de las plantas, así como de sus posibles efectos secundarios. En años recientes se han reportado los efectos tóxicos de varias plantas medicinales sobre el desarrollo preimplantacional de ratón (Benavides et al., 1998; Benavides et al., 1999), muchas de las cuales producen malformaciones y alteraciones en el desarrollo embrionario. Ruta graveolens "ruda", Origanum vulgare "orégano" y Persea americana "palta" son usadas folkloricamente para aliviar cólicos menstruales y como abortivos (Estrella, 1995). El objetivo del presente trabajo es evaluar in vivo el efecto del extracto acuoso de orégano, ruda y palta al $20 \%$ sobre la mortologia y el desarrollo de embriones preimplantacionales de ratón.

\section{ABSTRACT}

The growing interest in natural medicine makes it necessary to study plant properties as well as their possible secondary effects. In recent years the toxic effects of many medicinal plants on the preimplantational mouse embryo development have been studied. Many of them produce malformations and alterations in the embryonic development. Ruta graveolens "ruda", Origanum vulgare "oregano" and Persea americana "palta" are used in rural areas to menstrual colic and to provoke abortion (estrella, 1995). This study is aimed at assessing "in vivo" the effect of extracts of "oregano", "ruda" and "palta" to $20 \%$ on the morphology and growth of preimplantational mouse embryos.

Todas las plantas fueron obtenidas de los mercados de Lima e identificadas mediante las claves vigentes. En el laboratorio se procedió al secado (colocándolas en la estufa a $60{ }^{\circ} \mathrm{C}$ durante $24 \mathrm{~h}$ ) de las hojas de ruda y orégano $y$, en el caso de la palta, la pepa rallada.

Se usaron ratones Albino-Swiss mantenidos en nuestro laboratorio bajo condiciones de

\footnotetext{
Laboralorio de Reproducción y Biotogia del Desarrollo. Facullad de Ciencia Biologicas, Universidad Nacional Mayor de San Miarcos. Av. Venezuela Sin Casilla Postal 14-002, Lima 14, Perú e-mail: vbenavides23@hotmail.com
}

bioterio de 14 horas luz y 10 oscuridad. Hembras de 6 a 8 semanas de edad fueron cruzadas con machos fértiles de 8 a 12 semanas, comprobándose la cópula al día siguiente por la presencia del tapón vaginal. Las hembras preñadas fueron separadas en cuatro grupos: Grupo contro (al que se le suministro diariamente ad libitum agua potable); a los demás grupos se suministro una infusión al $20 \%$ $(p / v)$ de ruda, palta y orégano. El extracto acuoso en todos los casos, fue preparado colocando $2 \mathrm{~g}$ de cada planta en $10 \mathrm{ml}$ de agua potable previamente calentada a $60^{\circ} \mathrm{C}$, se dejó 
en infusión durante 15 minutos mas a la misma temperatura, se dejo enfriar y decantar, se separó el sobrenadante, el cual fue suministrado a los animales en las mismas condiciones que el grupo control, hasta las 83 horas postcópula (hpc). La infusión fue renovada diariamente. Las hembras fueron sacrificadas por dislocación cervical, y se les extirparon los oviductos y los cuemos uterinos; luego los embriones fueron obtenidos por perfusión, mediante lavados sucesivos con Buffer Fosfato Salino (PBS; SIGMA) pH 7,4. Los embriones se examinaron en un microscopio de contras- te de fase y se determinó el grado de viabilidad realizando una evaluación morfológica considerando lo siguiente (Dorn y Kramer, 1987): Grado 1: el embrión es redondo y no tiene blastómeros libres; Grado 2: El embrión tiene blastómeros libres; Grado 3: el embrión tiene blastómeros libres y malformaciones severas; Degenerados: el embrión pierde su forma esférica, además presenta membrana(s) celular(es) rotas. En la tabla 1 los embriones de grado 3 y degenerados son considerados anormales. A los resultados se aplicó la prueba de $X^{2}$.

Tabla 1. Calidad embrionaria y alteraciones en el desarrolio en porcentaje de embriones preimplantacionales en los grupos control, ruda, palta y orégano.

\begin{tabular}{llllll}
\hline & Grado 1 & Grado 2 & Grado 3 & \multicolumn{2}{c}{ Degenerado Anormales } \\
\hline CONTROL & $42,86(33)$ & $42,86(33)$ & $10,39(8)$ & $3,90(3)$ & $14,29(11)$ \\
RUDA 20\% & $51,02(25)$ & $24,49(12)^{\star}$ & $24,49(12)^{*}$ & $0,00(0)^{\star}$ & $24,49(12)^{*}$ \\
PALTA 20\% & $55,38(36)$ & $29,23(19)^{\star}$ & $3,08(2)^{*}$ & $12,31(8)^{\star}$ & $15,39(10)$ \\
ORÉGANO 20\% & $52,00(26)$ & $38.00(19)$ & $2,00(1)^{*}$ & $8,00(4)^{*}$ & $10,00(5)$ \\
\hline
\end{tabular}

Números en paréntesis son números de embriones evaluados.

Significativamente diferente del grupo control $(p<0.05)$.

Tabla 2. Porcentaje de embriones por estadios.

\begin{tabular}{|c|c|c|c|c|c|c|}
\hline & 1-8 cell & M. no Comp. & M. Comp. & Blast. Ini. & Blast. Tar. & Blast. Exp. \\
\hline CONTROL & $5,2(4)$ & $2,60(2)$ & $28,57(22)$ & $16,88(13)$ & $29,87(23)$ & $16,88(13)$ \\
\hline RUDA $20 \%$ & $0,00(0)$ & $4,08(2)$ & $46,94(23)^{\star}$ & $6,12(3)^{\star}$ & $30,61(15)$ & $12,24(6)$ \\
\hline PALTA $20 \%$ & $12,32(8)^{\star}$ & $0,00(0)$ & $32,31(21)$ & $15,38(10)$ & $33,85(22)$ & $6,15(4)^{*}$ \\
\hline ORÉGANO $20 \%$ & $6,00(3)$ & $4,00(2)$ & $44,00(22)^{\star}$ & $4,00(2)^{\star}$ & $24,00(12)$ & $18,00(9)$ \\
\hline
\end{tabular}

Significativamente diferente del grupo control $(p<0,05)$.

Nuestros resultados evidenciaron una disminución significativa de embriones normales (grado 2) en los grupo ruda y paita (Tabla 1). El grupo ruda presenta un porcentaje significativamente mayor de embriones anormales que es de $24,49 \%$ frente a $14,29 \%$ en el grupo control (Tabla 1). En el grupo palta se observa un aumento de embriones degenerados que es de $12,31 \%$ frente a $3,90 \%$ en el grupo control (Tabla 1). En cuanto al retraso en el desarrollo embrionario se observa un in- cremento de embriones de 1 a 8 células en el grupo palta y a su vez se observa un descenso en la ocurrencia de estadios posteriores como blastocisto expandido (Tabla 2). Los embriones de los grupos ruda y orégano muestran un incremento en los estadios de mórula compactada y blastocisto inicial evidenciándose un atraso ligero en el desarrollo embrionario (Tabla 2). En el grupo orégano se observa un $10 \%$ de embriones anormales, porcentaje menor al observado en el grupo control 
que presenta un $14,29 \%$ esta diferencia no es significativa.

Paulini et al. (1991) reportaron una actividad mutagénica de $R$. graveolens propiedad que se le atribuye a alcaloides de la familia de los acridones, lo que apoya la hipótesis de un efecto tóxico de $R$. graveolens. Así también se han reportado efectos anticonceptivos en ratas, y no se ha observado el mismo efecto en hámster (Gandhiet al., 1991). Algunos autores proponen que el aceite de la semilla de $P$. americana incrementa la actividad de la fosfatasa alcalina; esta enzima está relacionada con procesos y mecanismos de diferenciación temprana, a partir del estadio de 2 células (Werman et al., 1989), lo que podría alterar el desarrollo embrionario normal. También hay reportes de que $O$. vulgare tiene efectos antioxidantes, y se atribuye este efecto parcialmente a la presencia del ácido rosmarínico, que le estaría confiriendo un poder protector contra daño celular por oxidación (Lamaison, etal., 1990). Además se ha reportado que $O$. vulgare posee actividad antimutagénica (Lagouri y Boskou, 1996), lo que explicaría la menor incidencia de embriones anormales encontrados en el grupo orégano.

\section{LITERATURA CITADA}

Benavides V., Gutiérrez J., D’Arrigo G. \& Pino J. 1998. Libro de resúmenes VII Reunión Científica del Instituto de Ciencias Biológicas "Antonio Raimondi": 44. Lima-Perú.

Benavides V., Gutiérrez J., \& Pino J., 1999. Libro de resúmenes VIII Reunión Científica del Instituto de Ciencias Biológicas "Antonio Raimondi": 119. Lima-Perú.

Dorn CG \& Kramer DC. 1987. Bovine embryo gradient. Texas A \& E University, USA.

Estrella E. 1995. Tratado de Cooperacion Amazonica, Lima, pp. 151-187.

Gandhi M., Lal R., Sankaranarayanan A y Sharma PL. 1991. J. Ethnopharmacol 34: 49-59.

Lamaison JL, Petitjean-Freytget C. \& Carnat A. 1990. Ann Pharma Fr 48: 103-8.

Lagouri V. \& Boskou D.1996. Int J Food Sci Natu. 47: 493-7

Paulini H., Popp R., Schimmer O., Ratka O y Roder E. 1991. Planta Med 57:59-61.

Werman MJ, Mokady S., Neeman I., Aualaender L \& Zeidler A. 1989. Food Chem Toxicol 27:279-82. 